\title{
The role of social support on physical activity behaviour in adolescent girls: a systematic review and meta-analysis
}

\author{
Yvonne Laird ${ }^{1 *}$, Samantha Fawkner ${ }^{1}$, Paul Kelly', Lily McNamee ${ }^{2}$ and Ailsa Niven ${ }^{1}$
}

\begin{abstract}
Adolescent girls have been targeted as a priority group for promoting physical activity levels however it is unclear how this can be achieved. There is some evidence to suggest that social support could impact the physical activity levels of adolescent girls, although the relationship is complex and not well understood. We aimed to systematically review and meta-analyse the relationship between social support and physical activity in adolescent girls, exploring how different types and providers of social support might influence the relationship. Articles were identified through a systematic search of the literature using 14 electronic databases, personal resources, grey literature, and reference lists of included studies and previous reviews. Search terms representing social support, physical activity and adolescent girls were identified and used in various combinations to form a search strategy which was adapted for different databases. Cross-sectional or longitudinal articles published in English that reported an association between social support and physical activity in adolescent girls between the ages of 10 to 19 years were included. Studies that focused only on clinical or overweight populations were excluded. Data extraction was carried out by one reviewer using an electronic extraction form. A random $25 \%$ of included articles were selected for data extraction by a second reviewer to check fidelity. Risk of bias was assessed using a custom tool informed by the Critical Appraisal Skills Programme Cohort Study Checklist in conjunction with data extraction. Cross-sectional results were meta-analysed and longitudinal results were presented narratively. Small but significant associations between all available providers of total social support (except teachers) and physical activity were found ( $r=.14-.24)$. Small but significant associations were also identified for emotional, instrumental and modelling support for some providers of support $(r=.10-.21)$. Longitudinal research supported the cross-sectional analyses. Many of the meta-analysis results suggested high heterogeneity and there was some evidence of publication bias, therefore, the meta-analysis results should be interpreted with caution. In conclusion, the meta-analysis results suggest that social support is not a strong predictor of physical activity in adolescent girls though parents and friends may have a role in enhancing PA.
\end{abstract}

Trial registration: PROSPERO 2014:CRD42014006738

Keywords: Physical activity, Social support, Adolescent girls, Systematic review

\section{Background}

The health benefits of regular physical activity (PA) are well documented [1], yet there are concerns about the low levels of PA in adolescents. It has been estimated that $80 \%$ of adolescents worldwide fail to achieve PA guidelines [2], with adolescent girls consistently identified as less active than boys [2-4]. There is also evidence

\footnotetext{
* Correspondence: Yvonne.Laird@ed.ac.uk

'Physical Activity for Health Research Centre (PAHRC), University of

Edinburgh, St Leonard's Land, Edinburgh EH8 8AQ, UK

Full list of author information is available at the end of the article
}

to suggest that activity levels during adolescence may track into adulthood [5]. As a result, interventions have been developed that aim to promote PA in adolescent girls, although these have had limited effect (6-8). Recent evidence also suggests that there are gender differences in correlates of physical activity in adolescents [9]. Therefore, understanding the correlates and determinants of PA specifically in adolescent girls is essential to inform the development of current and future interventions for this population [10]. 
A growing body of evidence focusing on correlates and determinants of PA in adolescent girls exists, and subsequently, research has been summarised by systematic reviews [11-14]. Consistent with a socio-ecological approach [15], these reviews have identified categories of PA correlates including personal, psychological, environmental and social correlates. Social support in particular has consistently emerged as positively related to PA in adolescent girls. Social support describes resources provided from interactions with significant others that can influence behaviour [16, 17]. These resources can be emotional (e.g. encouragement, praise), instrumental (e.g. equipment, financial), or informational support (e.g. advice, instruction) and they can be provided by various individuals (providers) within one's social network (e.g. friends, family, teachers) $[18,19]$. Within the PA literature, modelling (e.g. associations between activity levels of provider and child) and co-participation (e.g. performing physical activities together) have also been considered forms of social support [20, 21]. Table 1 outlines these different types of support. In social support measurement studies, social support typically refers to a composite score of one or more of these types of sub-types of support.

Numerous studies have focused on social support for PA in children and adolescents and these have also been systematically reviewed [14, 20, 22-28]. Most of these reviews have focused on parental influences with results suggesting positive significant associations between parent support and child and adolescent PA [20, 22-24, 26, 27]. Despite the lower prevalence of PA in adolescent girls, none of these reviews focused specifically on this group. Only two reviews considered gender and they found no significant differences between boys and girls, however, analyses only considered overall support [20, 27] and modelling [20] and were presented for both children and adolescents. There is some evidence to suggest the relationship between social support and PA might vary by age [23] and gender [29], therefore, considering these variables separately may better inform PA intervention development for adolescent girls.
Pugliese and Tinsley [27] and, later, Yao and Rhodes [20] conducted the two meta-analyses in the area. They both identified small to medium significant associations between parent support and youth PA $(r=.17$ and $r=.38$ respectively) and small but significant associations between parent modelling and youth PA $(r=.13$ and $r=.16$ respectively). Yao and Rhodes [20] also found that parental encouragement and co-participation were most strongly related to youth PA compared with praise, watching and logistic support, perhaps suggesting that different types of social support may influence PA differently. Neither metaanalysis considered all providers of social support. This limits our understanding about the relative importance of different types and providers of social support for adolescent girls' PA.

Yao and Rhodes [20] also considered how other variables moderated the effect sizes of the relationship. Specifically, they found that PA measure (e.g. objective/subjective) moderated one of the effect sizes, with subjective tools showing larger effects. Study quality, geographical location and age were also assessed but did not significantly moderate effect sizes. It is also possible that other factors not investigated could have influenced reported effect sizes. For example, there is some evidence to suggest that associations may vary according to type of PA (e.g. sports, active travel) [24]. Measurement of social support may also moderate effect sizes, as inconsistent methods of measuring social support and the use of non-validated scales has previously been highlighted as problematic in the literature [30]. Similarly, it is possible that effect sizes differ based on whether social support is reported by the child (perceived support) or reported by the provider (received support) For example, parents may believe that they are supporting their child to be active (received support) but if the child does not feel supported (perceived support) then the association with PA is likely to differ between perceived and received support.

To date, the only available evidence that has considered all providers and all types of social support on PA in young people adopted a semi-quantitative and narrative approach [22]. Whilst the findings from this review

Table 1 Types of social support for physical activity

\begin{tabular}{|c|c|}
\hline Type of support & Sub-types of support/description \\
\hline Emotional support & $\begin{array}{l}\text { Providing child with encouragement for physical activities; encouraging child to be active; talking to child about physical } \\
\text { activities; praise; watching child perform physical activities }\end{array}$ \\
\hline $\begin{array}{l}\text { Instrumental support } \\
\text { (logistic support) }\end{array}$ & $\begin{array}{l}\text { Financial support; providing transport to physical activities; providing equipment for child to be physically active } \\
\text { (e.g. bicycle) }\end{array}$ \\
\hline $\begin{array}{l}\text { Informational } \\
\text { support }\end{array}$ & Feedback on physical activities; providing instruction or advice to be physically active \\
\hline Co-participation & Performing activities with child (e.g. going for walks together) \\
\hline Modelling & Provider 'models' PA and child modifies their behaviour/associations between activity levels of provider and child \\
\hline Total social support & A composite score of social support, typically refers to one or more of the above sub-types of support \\
\hline
\end{tabular}


suggested that support from both parents and friends is positively associated with PA in adolescents, no comparison in effects sizes between providers and types of support was possible. Performing meta-analysis would allow us to compare effect sizes and establish if some types and providers of support are more strongly associated with PA in adolescent girls than others. Understanding these relationships more comprehensively could inform PA intervention design for adolescent girls. In particular, this analysis could inform the providers and types of social support that should be targeted in PA interventions for adolescent girls.

Therefore, the first aim of this study was to comprehensively map the literature to demonstrate the numbers of associations reported for different combinations of types and providers of social support. Secondly, where there was enough available evidence, we aimed to perform meta-analyses on effect size data for different providers and types of social support for adolescent girls' PA. Finally, we aimed to carry out moderator analyses on effect sizes for age, geographical location, social support measurement bias (e.g. high risk, low risk), who reported the social support (e.g. perceived or received support), PA measure (objective or subjective) and type of PA (e.g. active travel, sports).

\section{Methods}

This study followed the procedures for systematic reviews and meta-analysis outlined in the PRISMA statement [31]. A protocol for this review was prepared and registered with PROSPERO [32].

\section{Search strategy}

Literature published until January 2015 were synthesised and reviewed. The following electronic databases were searched to identify studies for inclusion: MEDLINE, PsychINFO, EMBASE, CABabstracts, Global Health, Allied and Complementary Medicine, SPORTDiscus, ERIC, CinAHL, Science Citation Index, Social Science Citation Index, the Cochrane library, Dissertations and Theses A\&I and the International Bibliography of the Social
Sciences. Additional articles were located using the reference lists of included articles and previously published reviews. Personal resources including the authors' own EndNote libraries and book chapters were consulted. Search terms included a combination of free text terms and subject headings relating to the target population, social support, and PA (see Table 2). The search strategy was adapted for each database and searches were logged and recorded. Pilot searches were conducted to improve the sensitivity and specificity of the final search strategies.

\section{Eligibility criteria}

Peer reviewed publications or doctoral theses published until January 2015 were included. No limitation was placed on start date. Studies were eligible for inclusion if: (1) data for adolescent girls between the ages of 10 to 19 years, or a mean age within this range, were reported (based on the World Health Organizations [33] definition of adolescence) (2) they included a measure of social support as an independent variable, (3) they included a measure of adolescent's PA as a dependent variable, and (4) they reported an association between PA and social support (e.g. quantitative studies reporting cross-sectional or longitudinal associations). Studies were excluded if (1) they focused only on clinical or overweight populations, (2) only a health related fitness measure was reported, or (3) they were not published in English.

\section{Screening}

Two reviewers independently screened search results against the inclusion and exclusion criteria. This was carried out in two stages. The initial stage involved screening titles and abstracts only, and full articles were located where titles and abstracts were identified as meeting the inclusion criteria. Any disagreements were discussed and resolved during a meeting with a third reviewer.

Table 2 Systematic review search terms

\begin{tabular}{lll}
\hline Target population & Social support & Physical activity \\
\hline Adolescen* & Social support & Sport* \\
Young people & (Family or peer or friend* or school) adj2 (support or encourage* or help or assist*) & Physical activit* \\
Youth & (emotion* or instruction* or information* or psychosocial) adj2 (support or encourage* or help or assist*) & Exercis* \\
Girl* & & \\
Female* & & \\
Teen* & & \\
School age* & &
\end{tabular}

* Search term truncated 


\section{Data extraction and risk of bias assessment}

Data from the included articles were extracted onto an electronic form, which was designed and piloted for this review. The extracted data included: general study information; participant characteristics; outcome characteristics for PA and social support; methods of analysis; and results. In conjunction with data extraction, included studies were assessed for risk of bias. The Critical Appraisal Skills Programme for cohort studies tool (CASP; www.casp-uk.net), a checklist based on a tool used previously in the PA literature [34], was used to guide risk of bias assessment. Four categories relating to study sampling and instrument validation were identified that might pose a risk of bias to the type of studies likely to be included in the review, including: selection bias, PA measurement bias, social support measurement bias, and confounding variables. Each category within each study was then assigned as having a 'low', 'high' or 'unclear' risk of bias using an 8-item checklist of predetermined assessment thresholds (see Additional file 1). The risk of bias assessment was not used to exclude or weight studies within the review. Data extraction and risk of bias assessment was completed by one author. To estimate accuracy, a second reviewer carried out data extraction and risk of bias assessment on a random $25 \%$ of the included studies. Following this, any disagreements were resolved during a meeting with a third reviewer. The inter-rater reliability for the two reviewers was found to be Kappa $=0.62$, suggesting a good level of agreement between the two reviewers [35]. Therefore, the data extraction and risk of bias accuracy of one reviewer was deemed to be acceptable.

\section{Effect size calculation}

Random effects meta-analyses were performed using Comprehensive Meta-Analysis Software Version 3.0 [36] to estimate pooled associations between provider and types of social support and PA in adolescent girls. Adjusted (where available) and non-adjusted (if adjusted not reported) standardised effect size metrics or odds ratios were entered into Comprehensive Meta-Analysis (e.g. bivariate correlations, standardised regression coefficients). In cases where standardised effect sizes were not available, if available, $p$-values and sample sizes were entered into Comprehensive Meta-Analysis and the effect size was back computed. If only non-standardised effect sizes were available, studies were not metaanalysed. Where a study reported more than one effect size for one association (e.g. parent support on PA) an overall effect size was included in the meta-analysis. If this was not available (for example, effect sizes were separated by ages and not reported overall) then more than one effect size for a study was entered into the metaanalysis and highlighted in the results table. In cases where multiple forms of PA were reported then moderate-to-vigorous PA (MVPA), or the closest form of activity to MVPA, was included in the meta-analysis. Effect sizes were converted to the Fisher's z scale, and all analyses were performed using the transformed values before being converted back to correlations to present the results. Pearson's $r$ was selected as the effect size metric to report the results and interpretation of the results were based on Cohen's criteria for small $(>0.10)$, moderate $(>0.30)$ and large $(>0.50)$ effect sizes [37]. Meta-analyses were performed for different types and providers of social support, providing at least 3 studies reported results on the combination of provider and type of support. Previous reviews informed the selection of six possible moderators of effect sizes (see Additional file 2) [20, 24]. Effect sizes were assessed for these proposed moderators by meta-regression including age, geographical location, social support measurement bias, who reported the social support (e.g. perceived or received support), PA measure (e.g. subjective or objective) and PA type (e.g. MVPA, sport) when at least six studies were included in the meta-analysis. Who reported social support was not assessed as a moderator for modelling. This was because modelling was measured by three mechanisms: self-report by provider, child reported modelling, and using objective measures. Use of objective measures is assessed as a separate moderator, and it was not possible to complete the analyses only for the subjective measures.

\section{Longitudinal studies}

Longitudinal studies were not included in the metaanalysis and were presented narratively. This was deemed the most appropriate way to represent the longitudinal data due to the varied analyses performed. For example, the predictive effect of baseline social support on future PA is not directly comparable to change in social support and PA over time. It was, therefore, deemed inappropriate to statistically pool these findings.

\section{Results}

A total of 6647 records were identified from electronic and manual searches, of which 84 met the inclusion criteria (see Fig. 1). Of these, data from 73 studies were included in the meta-analysis and data from 16 longitudinal studies were included in the narrative synthesis. Six cross-sectional studies were not included in the meta-analysis because there were not enough data to perform a meta-analysis [38-41] or because data could not be meta-analysed [42, 43]. Included studies were published between 1986 and 2014. The majority of studies were conducted in the USA (55\%). Other studies were conducted in Europe (15\%), Australia (12\%), Asia 


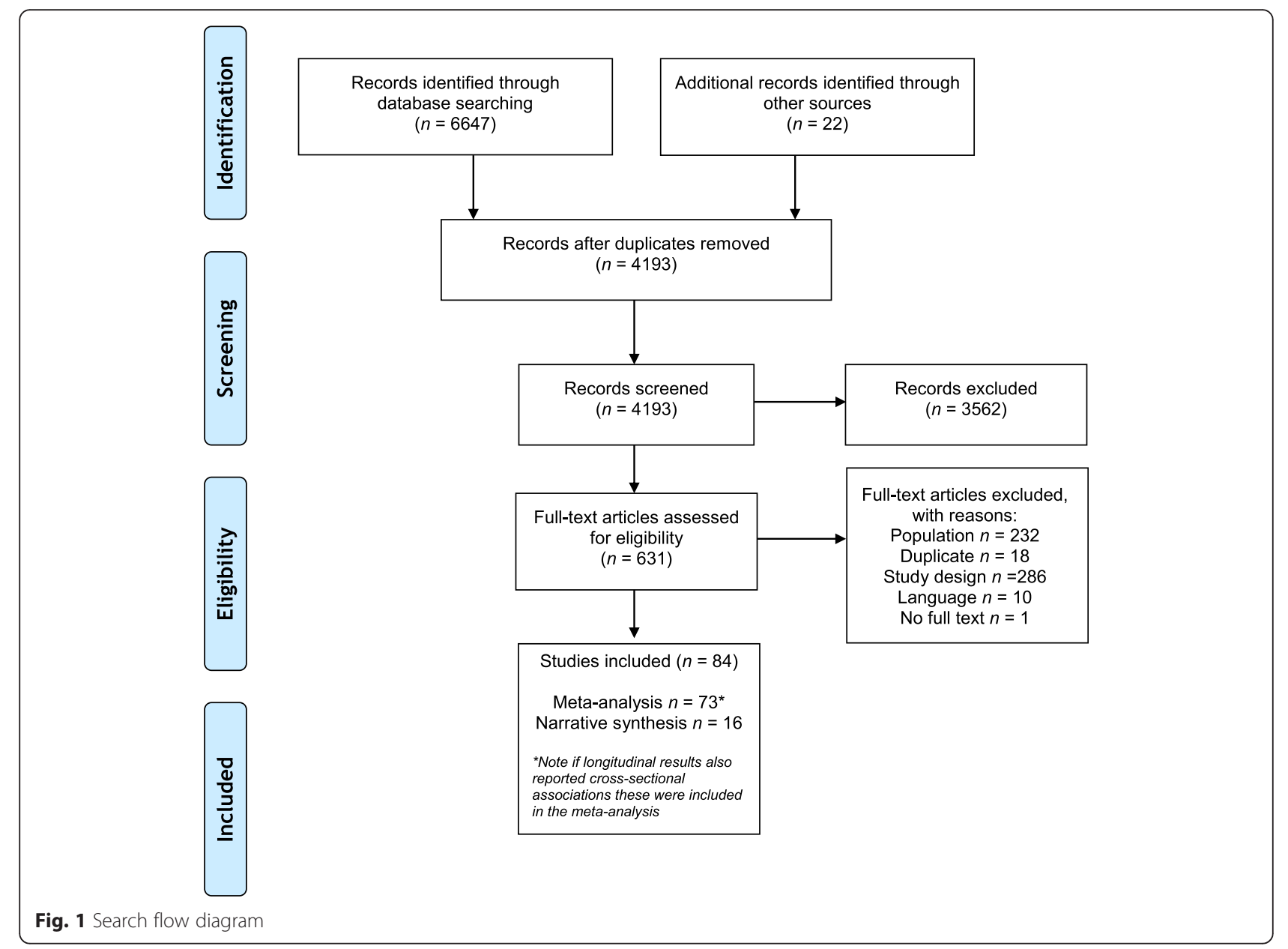

(8\%), Canada (7 \%), and South America (2\%). Most studies were cross-sectional in design $(81 \%)$, measured PA subjectively (71\%), and included participants aged between 13 and 15 years (52\%) (see Additional file 3). Included studies were assessed for risk of bias (see Fig. 2). As shown in the figure, most studies were of high risk of selection bias or did not report the relevant information on study selection. The majority of studies (75\%) did not control for all the proposed confounding variables in the risk of bias assessment and just over half of the included studies used a validated tool to measure social support (see Fig. 2).

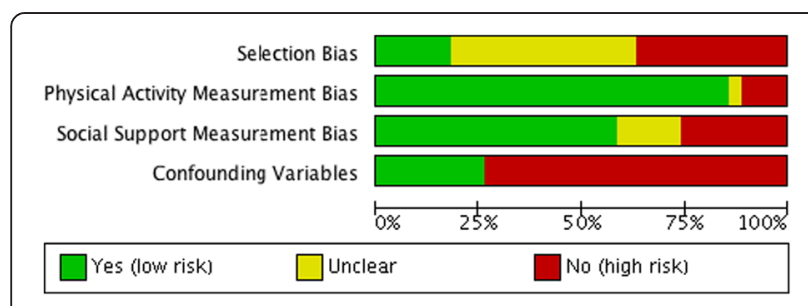

Fig. 2 Risk of bias of included studies
Table 3 provides an overview of the associations reported by the included studies, representing the combinations of associations available for 21 different providers and 14 types of social support for adolescent girls. Associations were predominantly reported for total social support by all providers, parents, family and friends on adolescent girls' PA. Total social support refers to an overall measure of social support for PA, this could include various sub-types of social support. Similarly, 'all providers' refers to studies that have not specified a provider of social support or have combined providers (e.g. parents, friends) using a composite score for social support. Associations were also commonly reported for modelling, particularly for parents, mothers, fathers and friends. Associations for other types of support such as emotional, instrumental or informational support were rarely reported and some providers of support were not investigated by many researchers (such as teachers, coaches and siblings) (see Table 3).

\section{Total social support}

The relationships between different providers of total social support and PA in adolescent girls were estimated by random effects meta-analysis (see Table 4). 
Table 3 Number of social support associations with adolescent girls' physical activity reported by provider and type

\begin{tabular}{|c|c|c|c|c|c|c|c|c|c|c|c|c|c|c|}
\hline \multirow[t]{2}{*}{ Provider } & \multirow{2}{*}{$\begin{array}{l}\text { Total } \\
\text { support }\end{array}$} & \multicolumn{5}{|c|}{ Emotional support ${ }^{\mathrm{a}}$} & \multicolumn{4}{|c|}{ Instrumental support ${ }^{\mathrm{b}}$} & \multirow[t]{2}{*}{ Modelling } & \multirow[t]{2}{*}{ Co-participation } & \multirow[t]{2}{*}{ Guiding } & \multirow[t]{2}{*}{ Informationa } \\
\hline & & $\mathrm{Em}$ & En & $\operatorname{Pr}$ & $\mathrm{Ta}$ & W & $\ln$ & $\operatorname{Tr}$ & $\mathrm{F}$ & $\mathrm{L}$ & & & & \\
\hline All providers & 12 & & & & & & & & & & 1 & 1 & & \\
\hline Parents & 14 & & 7 & & 1 & & 2 & 3 & 1 & & 14 & 4 & 1 & \\
\hline Family & 33 & 1 & 1 & 1 & & & 1 & & & & & 1 & & 1 \\
\hline Mother & 5 & & 4 & & & 1 & 1 & & & 3 & 11 & & & \\
\hline Father & 5 & & 3 & & & & 1 & & & 2 & 9 & 1 & & \\
\hline Friend & 35 & & 1 & & & & & & & & 10 & & & \\
\hline Teacher & 6 & & 1 & & & & 1 & & & & 1 & & & \\
\hline Sibling & 2 & & & & & & & & & & & & & \\
\hline Brother & & & & & & & & & & & 1 & & & \\
\hline Sister & & & & & & & & & & & 1 & & & \\
\hline Best friend & & & & & & & & & & & 1 & & & \\
\hline Boy peers & 2 & & 1 & & & & & & & & 1 & & & \\
\hline Female peers & 1 & & 1 & & & & & & & & 1 & & & \\
\hline Adult & & & & & & & & & & & 1 & & & \\
\hline Coach & 1 & & & & & & & & & & 1 & & & \\
\hline Classmate & & & & & & & & & & & 1 & & & \\
\hline Boy/girlfriend & & & & & & & & & & & 1 & & & \\
\hline Primary caregiver & & & & & & & & & & & 1 & & & \\
\hline First nominated friend & & & & & & & & & & & 1 & & & \\
\hline Second nominated friend & & & & & & & & & & & 1 & & & \\
\hline Third nominated friend & & & & & & & & & & & 1 & & & \\
\hline
\end{tabular}

${ }^{a} E m$ Emotional, En Encouragement, Pr Praise, Ta Talking, $W$ Watching

${ }^{\mathrm{b}}$ In Instrumental, $\operatorname{Tr}$ Transport, $F$ Financial, L Logistic

Small but significant associations were identified for every available provider of social support except teachers on adolescent girls PA $(r=0.14-0.24)$. However, there was considerable heterogeneity for most of the associations suggested by the significant Q-values and the high $I^{2}$ statistics.
Moderator analyses did not find any of the proposed moderators to be significant for total support from all providers, parents or friends $(p>0.05)$. For family support, PA type was a significant moderator of the association between family support and PA. Associations for sports participation $(r=0.44$,

Table 4 Associations from meta-analysis of all providers and sub domains of providers of total social support with physical activity outcomes

\begin{tabular}{|c|c|c|c|c|c|c|c|c|c|c|c|}
\hline & \multirow[t]{2}{*}{ Reference numbers of included studies } & \multicolumn{5}{|c|}{ Effect size statistics } & \multicolumn{4}{|c|}{ Heterogeneity statistics } & \multirow{2}{*}{$\begin{array}{l}\text { Publication bias } \\
\text { Fail safe } N\end{array}$} \\
\hline & & k & $r$ & SE & $s^{2}$ & $95 \% \mathrm{Cl}$ & $\bar{Z}$ & Q & $\tau^{2}$ & $P^{2}$ & \\
\hline All providers & {$[40,49,57,58,65,70-76]$} & 12 & 0.237 & 0.012 & 0.000 & $0.150,0.321$ & $5.21^{* * *}$ & $76.062^{* * *}$ & 0.017 & 85.54 & 555 \\
\hline Parents & {$[48,77-89]$} & 14 & 0.192 & 0.012 & 0.000 & $0.108,0.273$ & $4.50^{* * *}$ & $116.43^{* * *}$ & 0.020 & 88.83 & 513 \\
\hline Family & {$[50,52,73,76,90-106]^{a}$} & 32 & 0.136 & 0.009 & 0.000 & $0.081,0.191$ & $4.79^{* * *}$ & $420.96^{* * *}$ & 0.023 & 92.40 & 1815 \\
\hline Mother & {$[59,70,107]$} & 3 & 0.223 & 0.004 & 0.000 & $0.163,0.280$ & $7.20^{* * *}$ & 1.974 & 0.000 & 0.000 & 31 \\
\hline Father & {$[59,70,107]$} & 3 & 0.161 & 0.003 & 0.000 & $0.101,0.219$ & $5.25^{* * *}$ & 1.119 & 0.000 & 0.000 & 17 \\
\hline Friend & $\begin{array}{l}{[52,55,59,73,78,79,86,88} \\
90,93-95,97,98,100,102-112]^{\mathrm{a}}\end{array}$ & 33 & 0.135 & 0.004 & 0.000 & $0.096,0.173$ & $6.75^{* * *}$ & $180.23^{* * *}$ & 0.009 & 82.24 & 1738 \\
\hline Teacher & {$[52,104,110]^{a}$} & 6 & 0.062 & 0.015 & 0.000 & $-0.051,0.174$ & 1.08 & $102.55^{* * *}$ & 0.019 & 95.12 & 3 \\
\hline
\end{tabular}

\section{${ }^{*} P<0.05, * * * P<0.001$}

$k=$ number of studies; $r=$ effect size; $\mathrm{SE}=$ standard error; $\mathrm{S}^{2}=$ variance; $95 \% \mathrm{Cl}=95 \%$ confidence interval; $Z=$ test of null hypothesis; $Q=$ total $\mathrm{Q}$-value used to assess heterogeneity; $\tau^{2}=$ between study variance; $l^{2}=$ the percentage of total variance across studies not attributed to sampling error; Fail safe $\mathrm{N}=$ the number of additional studies (in which the effect was zero) that would be needed to increase the meta-analysis $P$ value to above 0.5 . ${ }^{a}=$ More than one effect size included in the meta-analyses from the following studies [50, 91, 93, 99, 100] 
$95 \%$ CI 0.19-0.69) were significantly higher $(p<0.01)$ than MVPA $(r=0.04,95 \% \mathrm{CI}-0.06-0.14)$, total PA $(r=0.10,95 \%$ CI $-0.01-0.21)$, after school PA $(r=$ $0.03,95 \%$ CI $-0.16-0.22)$, and active travel $(r=-0.14$, $95 \%$ CI -0.40-0.12). There were not enough studies included in the mother, father or teacher support meta-analyses to perform moderator analysis.

\section{Sub-domains of social support by provider Emotional support}

The most commonly reported form of emotional social support was encouragement, with only five other studies reporting additional types of emotional social support (talking $n=1$, watching $n=1$, praise $n=1$, overall emotional support $n=1$ ). Due to these low numbers for other forms of emotional support, and because different forms of emotional support may influence PA in different ways, we decided to perform analyses only on associations between encouragement and PA (see Table 5).
Small but significant associations were identified for every provider of encouragement on adolescent girls PA $(r=0.10-0.21)$. However, there was significant heterogeneity for most of the associations except for father encouragement. Due to the low sample sizes in the meta-analyses, moderator analysis was only performed for parent encouragement and no significant moderators were identified $(p>0.05)$.

\section{Instrumental support}

Studies that provided associations between instrumental support and PA were less common; with providers including parents, mothers and fathers (see Table 5). Studies were included in the instrumental support metaanalyses if they reported on relationships between general instrumental support, transport, financial, or logistic support for PA. These types of instrumental support were combined to form a composite instrumental support effect size, due to the low numbers of individual

Table 5 Associations from meta-analysis of providers of sub-domains of support with physical activity outcomes

\begin{tabular}{|c|c|c|c|c|c|c|c|c|c|c|c|}
\hline & \multirow[t]{2}{*}{ Reference numbers of included studies } & \multicolumn{5}{|c|}{ Effect size statistics } & \multicolumn{4}{|c|}{ Heterogeneity statistics } & \multirow{2}{*}{$\begin{array}{l}\text { Publication } \\
\text { bias } \\
\text { Fail safe } N\end{array}$} \\
\hline & & k & $r$ & SE & $\mathrm{S}^{2}$ & $95 \% \mathrm{Cl}$ & $\bar{Z}$ & $Q$ & $T^{2}$ & $P^{2}$ & \\
\hline \multicolumn{12}{|c|}{ Encouragement } \\
\hline Parents & {$[45,82,113-117]$} & 7 & 0.103 & 0.006 & 0.000 & $0.032,0.173$ & $2.841^{*}$ & $31.29^{* * *}$ & 0.007 & 80.824 & 108 \\
\hline Mother & {$[70,115,118-120]$} & 5 & 0.194 & 0.015 & 0.000 & $0.111,0.275$ & $4.512^{* * *}$ & 8.222 & 0.004 & 51.349 & 53 \\
\hline Father & {$[70,115,120]$} & 3 & 0.211 & 0.003 & 0.000 & $0.153,0.266$ & $7.075^{* * *}$ & 1.126 & 0.000 & 0.000 & 36 \\
\hline \multicolumn{12}{|c|}{ Instrumental support } \\
\hline Parents & {$[45,105,115,121,122]^{a}$} & 6 & 0.169 & 0.002 & 0.000 & $0.131,0.206$ & $8.648^{* * *}$ & 5.545 & 0.000 & 9.822 & 107 \\
\hline Mother & {$[119,123-125]$} & 4 & 0.214 & 0.022 & 0.000 & $0.060,0.359$ & $2.703^{*}$ & $13.26^{*}$ & 0.019 & 77.37 & 26 \\
\hline Father & {$[119,124,125]$} & 3 & 0.234 & 0.050 & 0.002 & $-0.011,0.452$ & 1.875 & $12.827^{*}$ & 0.040 & 84.41 & 13 \\
\hline \multicolumn{12}{|c|}{ Modelling } \\
\hline Parents & $\begin{array}{l}{[45,52,74,82,86,87,92,96,105,113,116} \\
117,126,127]\end{array}$ & 14 & 0.130 & 0.011 & 0.000 & $0.049,0.209$ & $3.154^{*}$ & $105.788^{* * *}$ & 0.019 & 87.711 & 214 \\
\hline Mother & $\begin{array}{l}{[49,53,70,78,89,105,115,124,125,128,} \\
129]\end{array}$ & 11 & 0.079 & 0.012 & 0.000 & $-0.004,0.160$ & 1.874 & $104.625^{* * *}$ & 0.014 & 90.442 & 101 \\
\hline Father & {$[70,78,89,105,115,124,125,128,129]$} & 9 & 0.144 & 0.011 & 0.000 & $0.054,0.232$ & $3.128^{*}$ & $54.458^{* * *}$ & 0.014 & 85.310 & 131 \\
\hline Friends & {$[51,52,78,89,104,110,114,126,127,130]$} & 10 & 0.161 & 0.013 & 0.000 & $0.074,0.245$ & $3.615^{* * *}$ & $191.764^{* * *}$ & 0.017 & 95.307 & 505 \\
\hline \multicolumn{12}{|c|}{ Co-participation } \\
\hline Parents & {$[45,105,122,126]$} & 4 & 0.033 & 0.017 & 0.000 & $-0.102,0.168$ & 0.483 & 34.00 & 0.017 & 91.18 & 0 \\
\hline
\end{tabular}

$k=$ number of studies; $r=$ effect size; $\mathrm{SE}=$ standard error; $\mathrm{S}^{2}=$ variance; $95 \% \mathrm{Cl}=95 \%$ confidence interval; $Z=$ test of null hypothesis; $Q=$ total $\mathrm{Q}$-value used to assess heterogeneity; $\tau^{2}=$ between study variance; $l^{2}=$ the percentage of total variance across studies not attributed to sampling error; Fail safe $\mathrm{N}=$ the number of additional studies (in which the effect was zero) that would be needed to increase the meta-analysis $P$ value to above 0.5 . ${ }^{a}=$ More than one effect size included in the meta-analysis for study: [122] 
instrumental support associations reported. Significant associations were identified for parents and mother instrumental support on adolescent girls' PA ( $r=0.17-0.21)$, but father instrumental support was not significant $(r=0.23)$.

Due to the low sample sizes, moderator analysis was only performed for parent instrumental support. As only six studies were available, separate models had to be conducted for each proposed moderator. This identified age and geographical location as significant moderators of parent instrumental support. Studies conducted in the USA had larger effect sizes $(r=0.20,95 \%$ CI 0.16-0.24) than those conducted in Australia $(r=0.09,95 \%$ CI $0.01-0.18)$. Effect sizes were significantly higher $(p<0.05)$ for girls aged 13 to 15 years $(r=0.20,95 \%$ CI $0.16-0.25)$ compared with younger girls aged 10 to 12 years $(r=0.09$, 95 \% CI 0.01-0.18).

\section{Modelling and co-participation}

Small but significant associations were identified for parents, father, and friend modelling on adolescent girls PA $(r=0.13-0.16)$ (see Table 5). No significant associations were found for modelling by mothers or family modelling on adolescent girls' PA. However, there was significant heterogeneity in all of the associations. Few studies investigated associations between co-participation and adolescent girls PA. There were only enough studies reporting associations for parents, and parent coparticipation was not found to be significantly related to adolescent girls PA $(r=0.03)$.

Moderator analyses was performed for parent, mother, father, and friend modelling. No significant moderators were identified for parent, mother, or friend modelling $(p>0.05)$. The relationship between father and adolescent PA was also moderated by how the girls' PA was measured $(p<0.05)$. To demonstrate this, subjective measures showed higher effect sizes $(r=0.25,95 \% \mathrm{CI}$ 0.04-0.46) compared with objective measures $(r=-0.03$, $95 \%$ CI -0.28-0.22). There were not enough studies included in the parent co-participation meta-analysis to perform moderator analysis.

\section{Publication bias}

Funnel plots (available from corresponding author) were inspected for evidence of publication bias, which suggested possible publication bias for friend modelling and PA. Fail-safe $\mathrm{N}$ analysis was subsequently conducted. This found that 505 additional studies in which the effect was zero would be needed for the overall effect to be statistically insignificant. This suggests a possible skewed effect size. However, subsequent trim and fill analysis did not suggest it was necessary to trim studies from the analysis, therefore, the effect size remained the same. For other analyses, fail-safe $\mathrm{N}$ suggested that few additional studies $(<150)$ were needed for the overall effect to be statistically insignificant in many of the meta-analyses performed. This suggests a possible skewed effect size although this could be linked to low sample sizes in the meta-analyses.

\section{Longitudinal findings}

Longitudinal associations between social support and PA in adolescent girls were investigated in 16 studies [44-59]. Different methodological approaches were used to assess these associations. This included assessments of baseline social support as a predictor of follow-up PA, repeated cross-sectional analyses, and assessment of changes in social support and PA over time. The following section provides an overview of the results of these analyses.

\section{Total social support}

As shown in Table 6, a total of 12 studies examined the relationship between total social support and adolescent girls' PA longitudinally, of which 10 studies reported a positive association and two reported no association. Positive associations were identified for general providers $(n=1)$, parents $(n=2)$, family $(n=3)$ and friends $(n=4)$, whilst the two studies identifying no associations were for general providers.

\section{Sub-domains of social support}

Two studies investigated the relationship between encouragement and PA in adolescent girls longitudinally. One study found a positive association between mother encouragement and adolescent girls' PA, whilst the other found no association between parent encouragement and adolescent girls PA (see Table 6). One study investigated the relationship between instrumental support and PA, identifying a positive association between parent instrumental support and adolescent girls' PA. A total of 12 studies investigated the relationship between modelling and adolescent girls' PA. Of these, five studies identified a positive association, one study found a negative relationship and six studies identified no association between modelling and adolescent girls' PA. Three studies assessed the relationship between co-participation and PA in adolescent girls. Two studies assessed associations between parent co-participation and adolescent girls' $\mathrm{PA}$, one of which identified a positive association whilst the other found there to be no association. The last study identified a positive association between friend coparticipation and adolescent girls' PA (see Table 6).

\section{Discussion}

Social support has been identified as a possible modifiable correlate of PA that can be used to inform interventions to enhance PA levels of adolescent girls. This study provided an overview of current evidence of the relationship between different providers and types of social 
Table 6 Longitudinal associations between social support and physical activity in adolescent girls

\begin{tabular}{|c|c|c|c|c|c|c|c|c|c|c|c|c|c|c|c|}
\hline & \multicolumn{3}{|l|}{ Total support } & \multicolumn{3}{|c|}{ Encouragement } & \multicolumn{3}{|c|}{ Instrumental } & \multicolumn{3}{|c|}{ Modelling } & \multicolumn{3}{|c|}{ Co-participation } \\
\hline & + & - & 0 & + & - & 0 & + & - & 0 & + & - & 0 & + & - & 0 \\
\hline General providers & [58] & & {$[53,57]$} & & & & & & & & & [53] & & & \\
\hline Parents & [47] [48] & & & & & {$[45]$} & {$[45]$} & & & {$[52]$} & & {$[45]$} & {$[46]$} & & [45] \\
\hline Father & & & & & & & & & & {$[44,46]$} & & & & & \\
\hline Mother & & & & {$[44]$} & & & & & & & [49] & [44] & & & \\
\hline Family & {$[50,52,56]$} & & & & & & & & & & & {$[54]$} & & & \\
\hline Friends & {$[52,55,56,59]$} & & & & & & & & & {$[51,52]$} & & {$[54,56]$} & {$[56]$} & & \\
\hline
\end{tabular}

+ Positive association, - negative association, 0 no association; numbers presented in table represent references of included studies for each association

support and adolescent girls' PA. This adds to previous systematic reviews by presenting the current evidence on all providers and types of support for adolescent girls' PA, which has not previously been done (see Table 3 ). We found 21 different providers and 14 different types of social support presented in the literature. Whilst this could mean that there are a substantial number of possible combinations of providers and types of social support, the majority of the studies focused on total social support and modelling from parents, family and friends. There are a number of areas with limited or no research including informational support, watching and talking about PA, and social support from siblings. Whilst this may highlight areas where further research could be needed it also raises questions about whether it is feasible and informative to consider all these possible combinations of support. There may be a need to standardise and refine social support as a construct to improve comparability between types of support and providers within the literature.

\section{Total social support}

With regards the provision of total support, we identified small but significant associations that were similar in magnitude between family and friend total social support with the largest associations for all providers of support and adolescent girls' PA $(r=.24)$. This suggests that both friends and family influence adolescent girls' PA, however, the small associations suggest that total social support explains only a small amount of the variance in adolescent girls' PA behaviour.

Our findings both support and contest the findings from a recent meta-analysis by Yao and Rhodes [19] who identified positive associations between parent support and PA in children and adolescents $(r=.38)$. We identified more modest effect sizes than Yao and Rhodes [19] for parent support on adolescent girls' PA $(r=.19)$, which aligns more closely with a meta-analysis by Pugliese and Tinsley [27] $(r=.17)$. These differences could be attributed to several factors. Yao and Rhodes [19] and Pugliese and Tinsley [27] considered all children and adolescents, whereas we only synthesised associations reported for adolescent girls. It is possible that there are differences in observed effect sizes between older and younger children and boys and girls, although these were not identified as significant moderators in analyses by Yao and Rhodes [19]. Furthermore, the higher observed effect sizes identified by Yao and Rhodes [19] could partially be explained by their analysis procedures, as they corrected effect sizes for sampling and measurement error. This highlights that there is a positive association between parent support and adolescent girls' PA, although the effect sizes are small.

Our finding that effect sizes were similar in magnitude between parent and friend support variables on adolescent girls' PA was suprising because the nature of the relationship between children and their parents transforms significantly during adolescence [60]. Adolescents spend less time with their parents and more time with their friends [61], therefore, we anticipated that friends might be better positioned to influence adolescent girls' PA than parents. Despite the similar effect sizes between parent and friend social support and adolescent girls' PA, it is likely that ways in which parents and friends provide social support and influence activity levels are different. For example, friends might contribute to positive experiences in physical education or organised physical activities whilst parents could create a foundation for lifelong habits in PA in their children at an early age and provide support for their ongoing participation in PA during adolescence. Further research might investigate these possible mechanisms in more detail. No significant positive associations for teacher support on adolescent girls' PA were identified. However, only six studies were included in the meta-analysis, which limits our understanding of the relationship between teacher support and PA in adolescent girls. Similar findings were reported in a previous semi-quantitative review [22]. Teachers may, however, play a role in PA behaviour change when given the tools to do so as a recent randomised controlled trial found that teachers mediated the effectiveness of a PA intervention [62].

We also found that PA type moderated effect sizes for total family support with significantly larger associations 
identified for sports participation compared with MVPA, total PA, after school PA and active travel. This suggests that families may have a greater influence over organised domains of PA. This is perhaps not surprising given that transport, equipment and financial support from parents may be necessary to enable young people to take part in some organised sports. Previous research has also suggested the relationship between social support and PA may vary by type of PA [24]. Other influencing factors (e.g. friends or school infrastructure) may have a stronger role in predicting school-based PA or total PA. Given that girls have been found to take approximately $41-47 \%$ of steps during the school day [63] this is an important consideration for future research.

\section{Sub-domains of social support}

In relation to the different types of social support, metaanalyses showed small but significant associations for encouragement, instrumental support and modelling. For parents, we identified similar effect sizes for encouragement $(r=.10)$ and instrumental support $(r=.17)$ and we found that co-participation was not significantly related to PA $(r=.03)$. This does not support findings from Yao and Rhodes [20] who found that encouragement and coparticipation were most strongly related with PA in samples of male and female children and adolescents. This may be explained by differences in sample sizes, number of studies included in the meta-analyses, or it could be that the relationships are weaker when investigating only girls. However, these findings do highlight small but positive associations for encouragement and instrumental support and suggest both are important to a similar extent for adolescent girls' PA. There were not enough studies to meta-analyse these types of support for friend support variables although Mendonça and colleagues [22] found that friend encouragement and co-participation were most consistently associated with adolescents' PA. Future research may be needed to quantify the role of different types of friend support on adolescent girls' PA.

\section{Longitudinal findings}

The results of the longitudinal studies generally reflected cross-sectional findings. Change in total social support from families and friends was consistently related to changes in PA, suggesting that social support is a determinant of PA behaviour in adolescent girls. As previously noted, several study designs were used to assess associations between social support and PA longitudinally. These different study designs may reflect some of the differences in results observed. For example, some analyses used baseline social support to predict follow up PA, whilst others compared changes in social support with changes in PA. We would expect both social support and PA to change over time, therefore, comparing these study designs has limitations. There was less longitudinal evidence for different types of social support (e.g. emotional support) nonetheless results reflected crosssectional findings in that different types of support seemed to be less consistently associated with PA compared with total support.

\section{Limitations}

The meta-analysis findings should be interpreted with caution for two reasons. Firstly, the analysis did not account for possible indirect effects of social support. The observed effect sizes suggest that social support only explains a small amount of variance in adolescent girls' PA, however, our analysis did not take account of possible indirect effects of social support on PA. Given that some research has found that self-efficacy [64-66] and competence and value [67] mediates the relationship between social support and PA it is possible that social support indirectly influences PA through self-efficacy and other possible mediating constructs (e.g. enjoyment). Secondly, there was high heterogeneity between studies and some evidence of publication bias. The high heterogeneity statistics may in part be related to sampling error although it is likely that other variables moderated the size of the effects. Our moderator analysis showed that type of PA (e.g. sport, MVPA) predicted the effect size for total family support on adolescent girls' PA and the relationship between father and daughter PA was moderated by type of PA measures, with subjective measures demonstrating higher effect sizes than objective measures. There were no significant moderators identified for other meta-analyses performed. A previous meta-analysis by Yao and Rhodes [19] carried out moderator analysis and similarly found that subjective measures demonstrated higher effect sizes but they did not test for type of PA.

After performing moderator analysis there was still high heterogeneity between studies so it is likely that other factors not investigated also moderated effect sizes. These high heterogeneity statistics may in part reflect methodological inconsistencies within the literature on associations between social support and PA in adolescent girls. For example, whilst we tried to account for type of PA (e.g. total PA, MVPA, sports participation) and how PA was measured (e.g. subjective or objective measures), alongside other potential moderators, we were not able to account of the vast range of tools used to measure PA (e.g. different subjective measures, accelerometers, see Additional file 4). Whilst these tools all measure PA they are all inherently different with distinct purposes, therefore, it is possible this contributed to variances in the effect sizes and the high heterogeneity statistics. Similarly, social support was measured using various tools. The most commonly reported validated tools used included a scale originally developed for the 
Amherst Health and Activity Study and later validated $[68,69]$ and the Activity Support Scale [44]. However, in many cases, these scales were modified for use or authors used non-validated, custom scales to measure social support. This is problematic because this lack of consistency could lead to imprecise measurement, which has been previously recognised as a challenge in the literature [30]. This may also have contributed to variances in the effect sizes and the high levels of heterogeneity identified although our analysis did try to account for this. Furthermore, various analysis techniques were employed across the included studies (e.g. correlations, regressions, growth curve models). Some of these analyses controlled for confounding variables (e.g. ethnicity, age) whilst others did not. This may also have contributed to variances in the effect sizes and high heterogeneity statistics. It was not possible to account for this within our analyses, which is a limitation to our findings.

\section{Implications}

This review has highlighted several implications for future research. Firstly, measurement of social support is inconsistent. With a very high number of possible combinations of types and providers of support identified by this review there is a need to standardise measurement so that more informative comparisons can be made. Secondly, although social support explained only a small amount of variance in adolescent girls' PA there may be some merit in exploring and testing intervention strategies aimed at increasing different types of social support from friends and families and PA alongside other known determinants of PA in adolescent girls, consistent with a socio-ecological approach to PA behaviour change [15]. In particular, the strongest associations were evident for total social support (or multiple forms of support) from multiple providers of support. This highlights a potential need for interventions to increase girls' exposure to multiple types and providers of social support. As these findings are specific to adolescent girls, a mirror review should be conducted to understand the relative importance of different types and providers of social support for physical activity in boys.

\section{Conclusion}

Social support from friends, parents and families has a small but positive relationship with PA in adolescent girls and associations were generally similar in magnitude for different providers and types of social support. As the associations were small, other variables may be more important for adolescent girls' PA. However, the results suggests that overall support from parents and friends, as well as sub-domains of support such as encouragement, instrumental support and modelling, are all associated with adolescent girls' physical activity. The strongest association was identified for overall social support from all providers of support, which may suggest that being supported by various people in various ways is important for adolescent girls PA. There may, therefore, be promise in including social support components, alongside other known predictors (e.g. strategies to increase self-efficacy), in PA behaviour change interventions targeting adolescent girls. Further research examining the success of such interventions is therefore warranted.

\section{Additional files}

Additional file 1: Risk of bias assessment thresholds. (DOCX 14 kb)

Additional file 2: Moderators tested in meta-regression. (DOCX $12 \mathrm{~kb}$ )

Additional file 3: Characteristics of included studies. (DOCX 12 kb)

Additional file 4: Data extraction from included studies. (DOCX $233 \mathrm{~kb}$ )

Abbreviations

MPVA, moderate-to-vigorous physical activity; PA, physical activity

\section{Acknowledgements}

None.

Funding

Yvonne Laird is supported by the Economic and Social Research Council [grant number: ES/J500136/1]. Lily McNamee is supported by the Chief Scientist Office [grant number: DTF/12/12]. Ailsa Niven, Samantha Fawkner and Paul Kelly are employed by the University of Edinburgh. These funding sources had no role in the study design, analysis or interpretation of the data.

\section{Availability of data and materials}

The dataset supporting the conclusions of this article is included within the article (and its additional files).

\section{Authors' contributions}

AN, SF and YL conceived the study. YL was responsible for searching for studies and drafting the manuscript. All authors were involved in screening studies, data extraction, analysing and interpreting the data and revising the manuscript. All authors read and approved the final manuscript.

Competing interests

The authors declare that they have no competing interests.

Consent for publication

Not applicable.

Ethics approval and consent to participate

Not applicable.

\section{Author details}

${ }^{1}$ Physical Activity for Health Research Centre (PAHRC), University of Edinburgh, St Leonard's Land, Edinburgh EH8 8AQ, UK. ${ }^{2}$ School of Clinical Sciences, University of Edinburgh, Division of Psychiatry, Royal Edinburgh Hospital, Edinburgh EH10 5HF, UK.

Received: 24 November 2015 Accepted: 21 June 2016 Published online: 07 July 2016

\section{References}

1. Janssen I, LeBlanc AG. Systematic review of the health benefits of physical activity and fitness in school-aged children and youth. Int J Behav Nutr Phys Act. 2010;7:40

2. Hallal PC, Andersen LB, Bull FC, Guthold R, Haskell W, Ekelund U. Global physical activity levels: surveillance progress, pitfalls, and prospects. Lancet. 2012;380(9838):247-57. 
3. Gill V. Chapter 5: physical activity. In: Campbell-Jack D, Hinchliffe S, Bromley C, editors. The Scottish health survey 2014: volume 1: main report. Edinburgh: The Scottish Government; 2015.

4. Currie C, Zanotti C, Morgan A, Currie D, de Looze M, Roberts C, et al. Social determinants of health and well-being among young people: Health Behaviour in School-Aged Children (HBSC) study: international report from the 2009/2010 survey. Copenhagen: WHO Regional Office for Europe; 2012.

5. Telama R. Tracking of physical activity from childhood to adulthood: a review. Obes Facts. 2009;2(3):187-95.

6. Camacho-Miñano MJ, LaVoi NM, Barr-Anderson DJ. Interventions to promote physical activity among young and adolescent girls: a systematic review. Health Educ Res. 2011;26(6):1025-49.

7. The National Institute for Health and Care Excellence. Promoting physical activity for children: review 6 - interventions for adolescent girls NICE public health collaborating centre - physical activity. 2008

8. Pearson N, Braithwaite R, Biddle SJ. The effectiveness of interventions to increase physical activity among adolescent girls: a meta-analysis. Acad Pediatr. 2015:15(1):9-18.

9. Telford RM, Telford RD, Olive LS, Cochrane T, Davey R. Why Are girls less physically active than boys? findings from the LOOK longitudinal study. PLOS ONE. 2016;11(3):e0150041.

10. Sallis JF, Owen N, Fotheringham MJ. Behavioral epidemiology: a systematic framework to classify phases of research on health promotion and disease prevention. Ann Behav Med. 2000;22(4):294-8.

11. Standiford A. The secret struggle of the active girl: a qualitative synthesis of interpersonal factors that influence physical activity in adolescent girls. Health Care Women Int. 2013;34(10):860-77.

12. Biddle S, Atkin A, Cavill N, Foster C. Correlates of physical activity in youth: a review of quantitative systematic reviews. Int Rev Sport Exerc Psychol. 2011;4(1):25-49.

13. Biddle S, Whitehead S, O'Donovan T, Nevill M. Correlates of participation in physical activity for adolescent girls: a systematic review of recent literature. J Phy Act Health. 2005;2:423-34.

14. Sallis JF, Prochaska JJ, Taylor WC. A review of correlates of physical activity of children and adolescents. Med Sci Sports Exerc. 2000;32(5):963-75.

15. Sallis JF, Cervero RB, Ascher W, Henderson KA, Kraft MK, Kerr J. An ecological approach to creating active living communities. Annu Rev Public Health. 2006;27(1):297-322.

16. Langford CPH, Bowsher J, Maloney JP, Lillis PP. Social support: a conceptual analysis. J Adv Nurs. 1997;25:95-100

17. Sheridan $\mathrm{CL}$, Radmacher SA. Health psychology: Challenging the biomedical model. Oxford, United Kingdom: John Wiley \& Sons; 1992.

18. Heaney CA, Israel BA. Social networks and social support. In: Glanz K, Rimer BK, Viswanath K, editors. Health behavior and health education: theory, research and practice. 4th ed. San Francisco: Jossey-Bass; 2008.

19. Stroebe W, Stroebe M. The social psychology of social support. Social psychology: handbook of basic principles. New York: Guilford Press; 1996. p. 597-621.

20. Yao CA, Rhodes RE. Parental correlates in child and adolescent physical activity: a meta-analysis. International Journal of Behavioral Nutrition and Physical Activity. 2015;12(10).

21. Davison KK. Activity-related support from parents, peers, and siblings and adolescents' physical activity: Are there gender differences? J Phys Act Health. 2010;1(4):363-76.

22. Mendonça G, Cheng LA, Mélo EN, de Farias Júnior JC. Physical activity and social support in adolescents: a systematic review. Health Educ Res. 2014;29(5):822-39.

23. Beets MW, Cardinal BJ, Alderman BL. Parental social support and the physical activity-related behaviors of youth: a review. Health Educ Behav. 2010;37(5):621-44.

24. Edwardson CL, Gorely T. Parental influences on different types and intensities of physical activity in youth: a systematic review. Psychol Sport Exerc. 2010;11(6):522-35.

25. Fitzgerald A, Fitzgerald N, Aherne C. Do peers matter? a review of peer and/ or friends' influence on physical activity among American adolescents. J Adolesc. 2012;35(4):941-58.

26. Gustafson SL, Rhodes RE. Parental correlates of physical activity in children and early adolescents. Sports Med. 2006;36(1):79-97.

27. Pugliese J, Tinsley B. Parental socialization of child and adolescent physical activity: a meta-analysis. J Fam Psychol. 2007;21(3):331-43.
28. Maturo CC, Cunningham SA. Influence of friends on children's physical activity: a review. Am J Public Health. 2013;103(7):23-38.

29. Salvy S-J, De La Haye K, Bowker JC, Hermans RCJ. Influence of peers and friends on children's and adolescents' eating and activity behaviours. Phys Behav. 2012;106(3):369-78.

30. Davison KK, Masse LC, Timperio A, Frenn MD, Saunders J, Mendoza JA, et al. Physical activity parenting measurement and research: challenges, explanations, and solutions. Child Obes. 2013;9(s1):S103-9.

31. Moher D, Liberati A, Tetzlaff J, Altman DG. Preferred reporting items for systematic reviews and meta-analyses: the PRISMA statement. Br Med J. 2009;339:b2535.

32. Laird $Y$, Niven A, Fawkner S, McNamee L, Kelly P. The role of social support on the physical activity behaviour of adolescent girls: a systematic review of cross-sectional and longitudinal research. International Prospective Register of Systematic Reviews (PROSPERO). 2014;2014:CRD42014006738. Available from http://www.crd.york.ac.uk/ PROSPERO/display_record.asp?ID=CRD42014006738.

33. World Health Organization. Health for the world's adolescents: A second chance in the second decade Geneva, Switzerland 2014. WHO Press.

34. Barnett I, van Sluiis EMF, Ogilvie D. Physical activity and transitioning to retirement: a systematic review. Am J Prev Med. 2012;43(3):329-36.

35. Altman DG. Practical statistics for medical research. London: Chapman and Hall; 1991.

36. Borenstein $M$, Hedges $L$, Higgins J, Rothstein $H$. Comprehensive meta analysis version 3.0. Englewood: Biostat; 2014.

37. Cohen J. A power primer. Psychol Bull. 1992;112(1):155-9.

38. Edwardson CL, Gorely T, Pearson N, Atkin A. Sources of activity-related social support and adolescents' objectively measured after-school and weekend physical activity: Gender and age differences. J Phys Act Health. 2013;10(8):1153-8

39. Shokrvash B, Majlessi F, Montazeri A, Nedjat S, Rahimi A, Djazayeri A, et al. Correlates of physical activity in adolescence: a study from a developing country. Glob Health Action. 2013;6:6.

40. Sharma SV, Hoelscher DM, Kelder SH, Diamond PM, Day RS, Hergenroeder AC. A path analysis to identify the psychosocial factors influencing physical activity and bone health in middle-school girls. J Phys Act Health. 2009;6(5):606-16.

41. Voorhees CC, Murray D, Welk G, Birnbaum A, Ribisl KM, Johnson CC, et al. The role of peer social network factors and physical activity in adolescent girls. Am J Health Behav. 2005;29(2):183-90.

42. Bungum TJ, Vincent ML. Determinants of physical activity among female adolescents. Am J Prev Med. 1997;13(2):115-22.

43. Davison KK. Activity-related support from parents, peers, and siblings and adolescents' physical activity: Are there gender differences? J Phys Act Health. 2004;1(4):363-76.

44. Bauer K, Nelson M, Boutelle K, Neumark-Sztainer D. Parental influences on adolescents' physical activity and sedentary behavior: longitudinal findings from Project EAT-II. Int J Behav Nutr Phys Act. 2008:5(1):12.

45. Bradley R, McRitchie S, Houts R, Nader P, O'Brien M. Parenting and the decline of physical activity from age 9 to 15. Int J Behav Nutr Phys Act. 2011:8(1):33

46. Crawford D, Cleland V, Timperio A, Salmon J, Andrianopoulos N, Roberts R, et al. The longitudinal influence of home and neighbourhood environments on children's body mass index and physical activity over 5 years: the CLAN study. Int J Obes. 2010;34(7):1177-87.

47. Davison KK, Downs DS, Birch LL. Pathways linking perceived athletic competence and parental support at age 9 years to girls' physical activity at age 11 years. Res Q Exerc Sport. 2006;77(1):23-31.

48. Dewar DL, Plotnikoff RC, Morgan PJ. Testing social-cognitive theory to explain physical activity change in adolescent girls from low-income communities. Res Q Exerc Sport. 2013:84(4):483-91.

49. DiLorenzo TM, Stucky-Ropp RC, Vander Wal JS, Gotham HJ. Determinants of exercise among children. II. A longitudinal analysis. Prev Med. 1998;27(3):470-7.

50. Dowda M, Dishman RK, Pfeiffer KA, Pate RR. Family support for physical activity in girls from 8th to 12th grade in South Carolina. Prev Med. 2007:44(2):153-9.

51. Duncan SC, Duncan TE, Strycker LA, Chaumeton NR. A cohort-sequential latent growth model of physical activity from ages 12 to 17 years. Ann Behav Med. 2007;33(1):80-9. 
52. Graham DJ, Bauer KW, Friend S, Barr-Anderson DJ, Nuemark-Sztainer D. Personal, behavioral, and socioenvironmental correlates of physical activity among adolescent girls: cross-sectional and longitudinal associations. J Phys Act Health. 2014:11(1):51-61.

53. Kahn JA, Huang B, Gillman MW, Field AE, Austin SB, Colditz GA, et al. Patterns and determinants of physical activity in U.S. adolescents. J AdolesC Health. 2008;42(4):369-77.

54. Reynolds KD, Killen JD, Bryson SW, Maron DJ, Taylor CB, Maccoby N, et al. Psychosocial predictors of physical activity in adolescents. Prev Med. 1990;19(5):541-51.

55. Raudsepp L, Viira R. Changes in physical activity in adolescent girls: a latent growth modelling approach. Acta Paediatr. 2008;97(5):647-52.

56. Zook KR, Saksvig BI, Wu T, Young DR. Physical activity trajectories and multilevel factors among adolescent girls. J Adolesc Health. 2014:54(1):74-80.

57. Dishman RK, Dunn AL, Sallis JF, Vandenberg RJ, Pratt CA. Social-cognitive correlates of physical activity in a multi-ethnic cohort of middle-school girls: two-year prospective study. J Pediatr Psychol. 2010;35(2):188-98.

58. Dishman RK, Saunders RP, Motl RW, Dowda M, Pate RR. Self-efficacy moderates the relation between declines in physical activity and perceived social support in high school girls. J Pediatr Psychol. 2009;34(4):441-51

59. Kirby J, Levin KA, Inchley J. Parental and peer influences on physical activity among Scottish adolescents: a longitudinal study. J Phys Act Health. 2011;8(6):785-93.

60. Smetana JG, Campione-Barr N, Metzger A. Adolescent development in interpersonal and societal contexts. Annu Rev Psychol. 2006;57(1):255-84

61. Larson R, Richards M, Moneta G, Holmbeck G, Duckett E. Changes in adolescents' daily interactions with their families from ages 10-18: disengagement and transformation. Dev Psychol. 1996:32:744-54

62. Eather N, Morgan P, Lubans D. Social support from teachers mediates physical activity behavior change in children participating in the Fit-4-Fun intervention. Int J Behav Nutr Phys Act. 2013;10(1):68.

63. Tudor-Locke C, McClain J, Hart T, Sisson S, Washington T. Expected values for pedometer-determined physical activity in youth. Res Q Exerc Sport. 2009:80(2):164-74.

64. Peterson M, Lawman H, Wilson D, Fairchild A, Van Horn M. The association of self-efficacy and parent social support on physical activity in male and female adolescents. Health Psychol. 2013;32(6):666-74.

65. Motl RW, Dishman RK, Saunders RP, Dowda M, Pate RR. Perceptions of physical and social environment variables and self-efficacy as correlates of self-reported physical activity among adolescent girls. J Pediatr Psychol. 2007;32(1):6-12

66. Trost SG, Sallis JF, Pate RR, Freedson PS, Taylor WC, Dowda M. Evaluating a model of parental influence on youth physical activity. Am J Prev Med. 2003;25(4):277-82

67. Sabiston CM, Crocker PR. Exploring self-perceptions and social influences as correlates of adolescent leisure-time physical activity. J Sport Exerc Psychol. 2008;30(1):3-22.

68. Prochaska JJ, Rodgers MW, Sallis JF. Association of parent and peer support with adolescent physical activity. Res Q Exerc Sport. 2002;73(2):206-10.

69. Dishman RK, Hales DP, Sallis JF, Saunders R, Dunn AL, Bedimo-Rung AL, et al. Validity of social-cognitive measures for physical activity in middle-school girls. J Pediatr Psychol. 2010;35:72-88.

70. Brown BA, Frankel BG, Fennell M. Hugs or shrugs: parental and peer influence on continuity of involvement in sport by female adolescents. Sex Roles. 1989;20(7/8):397-412.

71. Frenn M, Malin S, Villarruel AM, Slaikeu K, McCarthy S, Freeman J, et al. Determinants of physical activity and low-fat diet among low income African American and Hispanic middle school students. Public Health Nurs. 2005;22(2):89-97.

72. Pis MB. Physical activity social support, self-efficacy, and self-definition in adolescents: a correlational cross-sectional comparative study [doctoral dissertation]. 2006

73. Williams RA. Psychosocial factors and physical activity among black adolescent females. 2010;Ed.D.:110.

74. Lenhart CM, Patterson F, Brown MD, O'Brien MJ, Nelson DB. Disparity in physical activity among urban youth: an ecologically guided assessment Am J Health Educ. 2014;45(4):219-28.
75. Ling J, Robbins LB, Resnicow K, Bakhoya M. Social support and peer norms scales for physical activity in adolescents. Am J Health Behav. 2014;38(6):881-9.

76. Thompson WM, Berry D, Hu J. A church-based intervention to change attitudes about physical activity among black adolescent girls: a feasibility study. Public Health Nurs. 2013;30(3):221-30.

77. Baskin ML, Thind H, Affuso O, Gary LC, LaGory M, Hwang SS Predictors of moderate-to-vigorous physical activity (MVPA) in African American young adolescents. Ann Behav Med. 2013;45 Suppl 1:S142-50.

78. Cheng LA, Mendonca G, de Farias JC. Physical activity in adolescents: analysis of the social influence of parents and friends. J Pediatr. 2014;90(1):35-41.

79. de Farias JC, Reis RS, Hallal PC. Physical activity, psychosocial and perceived environmental factors in adolescents from Northeast Brazil. Cad Saude Publica. 2014;30(5):941-51.

80. Jackson L, Cumming SP, Drenowatz C, Standage M, Sherar LB, Malina RM Biological maturation and physical activity in adolescent British females: the roles of physical self-concept and perceived parental support. Psychol Sport Exerc. 2013;14(4):447-54.

81. Ramanathan S, Crocker PRE. Correlates of physical activity among adolescent youth in India. Int J Sport Psychol. 2013;44(2):111-27.

82. Crimi K, Hensley LD, Finn KJ. Psychosocial correlates of physical activity in children and adolescents in a rural community setting. Int J Exerc Sci. 2009;2(4):230-42.

83. Dollman J, Lewis NR. Interactions of socioeconomic position with psychosocial and environmental correlates of children's physical activity: An observational study of South Australian families. International Journal of Behavioral Nutrition and Physical Activity. 2009;6(56).

84. Kurc AR, Leatherdale ST. The effect of social support and school- and community-based sports on youth physical activity. Can J Public Health. 2009:100(1):60-4.

85. Lee KS, Loprinzi PD, Trost SG. Determinants of physical activity in Singaporean adolescents. Int J Behav Med. 2010;17(4):279-86.

86. Patnode CD, Lytle LA, Erickson DJ, Sirard JR, Barr-Anderson D, Story M. The relative influence of demographic, individual, social, and environmental factors on physical activity among boys and girls. Int J Behav Nutr Phys Act. 2010:7:79.

87. Williams SL, Mummery WK. Links between adolescent physical activity, body mass index, and adolescent and parent characteristics. Health Educ Behav. 2011;38(5):510-20

88. Wu S-Y, Pender N, Noureddine S. Gender differences in the psychosocial and cognitive correlates of physical activity among Taiwanese adolescents: a structural equation modeling approach. Int J Behav Med. 2003;10(2):93-105.

89. Deflandre A, Lorant J, Gavarry O, Falgairette G. Physical activity and sport involvement in French high school students. Percept Mot Skills. 2001;92(1):107-20.

90. He L, Ishii K, Shibata A, Adachi M, Nonoue K, Oka K. Mediation effects of social support on relationships of perceived environment and selfefficacy with school-based physical activity: a structural equation model tailored for Japanese adolescent girls. Open J Prev Med. 2013;3(1):42-50

91. Young MD, Plotnikoff RC, Collins CE, Callister R, Morgan PJ. Social cognitive theory and physical activity: a systematic review and meta-analysis. Obes Rev. 2014;15(12):983-95.

92. Bauer KW, Neumark-Sztainer D, Fulkerson JA, Hannan PJ, Story M. Familial correlates of adolescent girls' physical activity, television use, dietary intake, weight, and body composition. Int. 2011;8:25.

93. Kelly EB, Parrs-Medina D, Pfeiffer KA, Dowda M, Conway TL, Webber LS, et al. Correlates of physical activity in black, Hispanic, and white middle school girls. J Phys Act Health. 2010;7(2):184-93.

94. Kitzman-Ulrich H, Wilson DK, Van Horn ML, Lawman HG. Relationship of body mass index and psychosocial factors on physical activity in underserved adolescent boys and girls. Health Psychol. 2010;29(5):506-13.

95. Krishnamoorthy JS. The transmission of physical activity and related cognitions among African-American adolescent females and their primary female caregiver [doctoral dissertation]. 2002.

96. Kuo J, Young DR, Voorhees CC, Haythornthwaite JA. Associations between family support, family intimacy, and neighborhood violence and physical activity in urban adolescent girls. Am J Public Health. 2007;97(1):101-3. 
97. Leslie E, Kremer P, Toumbourou JW, Williams JW. Gender differences in personal, social and environmental influences on active travel to and from school for Australian adolescents. J Sci Med Sport. 2010;13(6):597-601.

98. Morrissey JL, Wenthe PJ, Letuchy EM, Levy SM, Janz KF. Specific types of family support and adolescent non-school physical activity levels. Pediatr Exerc Sci. 2012;24(3):333-46.

99. Sallis JF, Prochaska JJ, Taylor WC, Hill JO, Geraci JC. Correlates of physical activity in a national sample of girls and boys in grades 4 through 12 . Health Psychol. 1999;18(4):410-5.

100. Sallis JF, Taylor WC, Dowda M, Freedson PS, Pate RR. Correlates of vigorous physical activity for children in grades 1 through 12: comparing parent-reported and objectively measured physical activity. Pediatr Exerc Sci. 2002;14:30-44.

101. Saunders RP, Motl RW, Dowda M, Dishman RK, Pate RR. Comparison of social variables for understanding physical activity in adolescent girls. Am J Health Behav. 2004;28(5):426-36.

102. Shafer AB. Psychosocial Determinants of Physical Activity in a Sample of Undergraduate College Students. 2012;Ph.D.:119.

103. Wenthe PJ, Janz KF, Levy SM. Gender similarities and differences in factors associated with adolescent moderate-vigorous physical activity. Pediatr Exerc Sci. 2009:21(3):291-304

104. Zakarian JM, Hovell MF, Hofstetter CR, Sallis JF, Keating KJ. Correlates of vigorous exercise in a predominantly low SES and minority high school population. Prev Med. 1994;23(3):314-21.

105. Graham DJ, Wall MM, Larson N, Neumark-Sztainer D. Multicontextual correlates of adolescent leisure-time physical activity. Am J Prev Med. 2014;46(6):605-16.

106. Eime RM, Harvey JT, Craike MJ, Symons CM, Payne WR. Family support and ease of access link socio-economic status and sports club membership in adolescent girls: a mediation study. International Journal of Behavioral Nutrition and Physical Activity. 2013;10(50).

107. Taymoori P, Rhodes RE, Berry TR. Application of a social cognitive model in explaining physical activity in Iranian female adolescents. Health Educ Res. 2010;25(2):257-67.

108. Lubans DR, Morgan PJ. Social, psychological and behavioural correlates of pedometer step counts in a sample of Australian adolescents. J Sci Med Sport. 2009;12(1):141-7.

109. Burns C, Murphy JJ, MacDonncha C. Year in school and physical activity stage of change as discriminators of variation in the physical activity correlate profile of adolescent females. J Phys Act Health. 2014;11(4):721-8.

110. Young D, Saksvig BI, Wu TT, Zook K, Xia L, Champaloux S, et al. Multilevel correlates of physical activity for early, Mid, and late adolescent girls. J Phys Act Health. 2014;11(5):950-60.

111. Huang WY, Wong SH, Salmon J. Correlates of physical activity and screenbased behaviors in Chinese children. J Sci Med Sport. 2013;16(6):509-14.

112. Beets MW, Pitetti KH, Forlaw L. The role of self-efficacy and referent specific social support in promoting rural adolescent Girls' physical activity. Am J Health Behav. 2007;31(3):227-37.

113. Canfield JA. Models of physical activity and sedentary behavior [doctoral dissertation]. 2012.

114. Leggett C, Irwin M, Griffith J, Xue L, Fradette K. Factors associated with physical activity among Canadian high school students. Int J Public Health. 2012;57(2):315-24.

115. Anderssen N, Wold B. Parental and peer influences on leisure-time physical activity in young adolescents. Res Q Exerc Sport. 1992;63(4):341-8.

116. Ploeg KAV, Kuhle S, Maximova K, McGavock J, Wu B, Veugelers PJ. The importance of parental beliefs and support for pedometer-measured physical activity on school days and weekend days among Canadian children. BMC Public Health. 2013:13:1132.

117. McGuire MT, Hannan PJ, Neumark-Sztainer D, Cossrow NHF, Story M. Parental correlates of physical activity in a racially/ethnically diverse adolescent sample. Journal of Adolescent Health. 2002;30(4,Suppl):253-61.

118. Beets MW, Vogel R, Chapman S, Pitetti KH, Cardinal BJ. Parent's social support for children's outdoor physical activity: Do weekdays and weekends matter? Sex Roles. 2007;56(1-2):125-31.

119. Wilson AN, Dollman J. Social influences on physical activity in AngloAustralian and Vietnamese-Australian adolescent females in a single sex school. J Sci Med Sport. 2009;12(1):119-22.

120. O'Loughlin J, Paradis G, Kishchuk N, Barnett T, Renaud L. Prevalence and correlates of physical activity behaviors among elementary schoolchildren in multiethnic, low income, inner-city neighborhoods in Montreal, Canada. Ann Epidemiol. 1999;9(7):397-407.

121. Morgan CF, McKenzie TL, Sallis JF, Broyles SL, Zive MM, Nader PR. Personal, social, and environmental correlates of physical activity in a bi-ethnic sample of adolescents. Pediatr Exerc Sci. 2003;15(3):288-301.

122. Pearson N, Timperio A, Salmon J, Crawford D, Biddle SJH. Family influences on children's physical activity and fruit and vegetable consumption. Int J Behav Nutr Phys Act. 2009;6:34.

123. Jago R, Davison KK, Brockman R, Page AS, Thompson JL, Fox KR. Parenting styles, parenting practices, and physical activity in 10- to 11-year olds. Prev Med. 2011;52(1):44-7.

124. Jago R, Wood L, Sebire SJ, Edwards MJ, Davies B, Banfield K, et al. School travel mode, parenting practices and physical activity among UK year 5 and 6 children. BMC Public Health. 2014;14(370).

125. Raudsepp $L$. The relationship between socio-economic status, parental support and adolescent physical activity. Acta Paediatr. 2006;95(1):93-8.

126. Price SM, McDivitt J, Weber D, Wolff LS, Massett HA, Fulton JE. Correlates of weight-bearing physical activity among adolescent girls: results from a national survey of girls and their parents. J Phys Act Health. 2008;5(1):132-45.

127. Keresztes N, Piko BF, Pluhar ZF, Page RM. Social influences in sports activity among adolescents. J R Soc Promot Health. 2008;128(1):21-5.

128. Gregson JF, Colley A. Concomitants of sport participation in male and female adolescents. Int JSport Psychol. 1986;17(1):10-22.

129. Raudsepp L, Viira R. Influence of parents' and siblings' physical activity on activity levels of adolescents. Eur J Phys Educ. 2000;5(2):169-78.

130. Sawka K, McCormack G, Nettel-Aguirre A, Blackstaffe A, Perry R, Hawe P. Associations between aspects of friendship networks, physical activity, and sedentary behaviour among adolescents. J Obes. 2014;2014:632689.

\section{Submit your next manuscript to BioMed Central and we will help you at every step:}

- We accept pre-submission inquiries

- Our selector tool helps you to find the most relevant journal

- We provide round the clock customer support

- Convenient online submission

- Thorough peer review

- Inclusion in PubMed and all major indexing services

- Maximum visibility for your research

Submit your manuscript at www.biomedcentral.com/submit
) Biomed Central 